\title{
Stenosis of Mechanical Colorectal Anastomosis - Risk Factors, Treatment
}

\author{
ZALAN BENEDEK ${ }^{1}$, NICOLAE SUCIU ${ }^{1 *}$, GHENADIE PASCARENCO ${ }^{1}$, \\ OFELIA PASCARENC ${ }^{2}$, SORIN SORLEA ${ }^{1}$, ORSOLYA BAUER ${ }^{1}$, \\ CRISTINA VELICHE ${ }^{3}$, MARIUS COROS ${ }^{1}$ \\ ${ }^{1}$ University of Medicine, Pharmacy, Sciences and Technology of Targu Mures, Department of Surgery, 1 Gheorghe \\ Marinescu Str., 540103, Targu Mures, Romania \\ ${ }^{2}$ University of Medicine, Pharmacy, Sciences and Technology of Targu Mures, Department of Gastroenterology, \\ 1 Gheorghe Marinescu Str., 540103, Targu Mures, Romania \\ ${ }^{3}$ Mures County Emergency Hospital, 50 Gheorghe Marinescu Str., 540136, Tirgu Mures, Romania
}

\begin{abstract}
The aim of the study was to highlight the incidence of anastomotic stenoses in mechanical colorectal anastomosis associated with colorectal cancer, as well as the risk factors and treatment options. We performed a retrospective evaluation of 203 patients who underwent mechanical colorectal anastomosis associated with colorectal cancer. Several factors related to the patients were analysed as the tumour and the treatment applied. A telephone survey was used, and symptomatic patients were examined endoscopically. The results underwent statistical analysis. A percentage of $37.44 \%$ of the patients have reported motility disorders. Stenosis was found in 7 (3.44\%) patients. It was defined as the narrowing of the lumen that cannot be pass through with a $12 \mathrm{~mm}$ endoscope. Gender, tumour and anastomosis relation to the anal verge, anaemia and perioperative radiation therapy had no statistically significant importance. We have found a statistically significant correlation $(P<0.05)$ for age under 60 years, obesity, tumour perforation and protective ileostomy. Patients were treated by rectal digital or pneumatic dilation and radial incisions. The results were favorable, only one case needed surgical intervention and recreating the anastomoses. Colorectal anastomotic stenosis is a late postoperative complication which influences the patients life quality. By being aware of the prognostic factors of this complication, we would be able to take preventive measures. Our results suggest that age under 60 years, obesity, tumour complication by perforation and protective ileostomy could be statistically significant factors for anastomotic stenoses. Surgical treatment must be reserved for refractory cases, and reanastomosis could be affected by greater risks than in the initial surgery.
\end{abstract}

Keywords: colorectal anastomosis, stenosis, stricture, cancer

\section{Introduction}

Mechanical suturing devices have fully proved their usefulness in many surgical fields, offering the possibility to create sutures and anastomoses in regions to which access is restricted such as those at the level of the pelvis or the oesophagus in abdominal surgery. They ensure the uniformity and standardisation of the suture, eliminating biases associated with surgeons skills.

The pathology that most often requires the use of mechanical suturing devices is digestive, in particular a colorectal one, and it adds a possibility for the development of the laparoscopic approach. On large trials using the same inclusion criteria as our study has, use of a circular stapler for performing colorectal anastomosis has been reported in over $50 \%$ of cases [1].

Next to the undeniable advantages it offers, use of staplers can also be associated with complications also encountered in manual anastomosis. In colorectal surgery, complications associated with anastomosis are the most challenging. An anastomotic fistula can endanger a patient's life due to its septic consequences. Although fewer in incidence and less severe, anastomotic risks also exist in the late postoperative period, represented especially by anastomotic stenosis. These may occur after both mechanical and manual suturing.

\footnotetext{
*email: suciu_nicolae_mg@yahoo.com
} 
Studies comparing mechanical anastomoses with manual ones, regardless of the level of anastomosis, have found no significant differences as to what concerns the incidence of the occurrence of such complications as anastomotic leakage, haemorrhages or anastomotic stenoses [1,2].

There is a permanent effort to develop and perfect these devices so that they become more and more secure in creating perfect anastomoses with the lowest possible susceptibility to complications. Nevertheless, no matter how perfectly a digestive anastomosis is performed, its progression and healing depend on a multitude of factors not restricted to those associated with the surgical technique employed.

\section{Objectives}

The aims of the study were pointing out risk factors that lead to the emergence of colorectal anastomotic stenoses after using circular staplers, as well as the methods for resolving said complications in a surgical clinic's own experience.

\section{Materials and methods}

We have performed a 10-year retrospective study (cases between 2008 and 2017) at a general surgery clinic. All patients with colorectal cancer operated during this period who underwent colorectal resection with mechanical anastomosis using a circular stapler were taken into consideration. The inclusion criteria for the study were patients discharged who accepted taking part in the study and for whom all the parameters investigated were correctly entered into their medical files. Cases in which postoperative death occurred were excluded, and so were those with anastomotic fistulae requiring conversion to Hartmann's operation, those with local tumour recurrence and those whose data had not been fully registered.

For each patient, the following criteria were taken into consideration: biometric data (age, gender, body mass index), tumour data (position of the tumour relative to the anal verge, TNM tumour stage, tumoral complications), data about surgical treatment (mechanical preparation of the colon, diameter of the circular stapler, type of anastomosis, distance of anastomosis from the anal verge, protective stoma), data about postoperative complications (anastomotic fistulae), data about the result of postoperative endoscopic investigations, data about oncological treatment (pre- and postoperative radiation therapy) and laboratory data (haemoglobin, blood glucose).

All patients discharged and surviving at the time of the study were contacted via telephone and asked for their consent to take part in the study. A telephone questionnaire was used which included 10 questions referring to intestinal transit emphasising symptoms of possible anastomotic stenosis, data about the treatment applied and postoperative radiation therapy. Patients in whom the diagnosis of anastomotic stenosis was established before the questionnaire were also included, and data about the treatment administered and case progression was recorded. Patients where symptomatology raised suspicion of anastomotic stenosis were invited to an endoscopic check-up (video ano-rectoscopy and rectosigmoidoscopy). Those in whom anastomotic stenosis was identified were treated conservatively by transanal hydrostatic balloon dilation, and the number, frequency and result of the dilations were monitored, with a single case requiring surgical reintervention.

Anastomotic stenosis was defined as the narrowing of the lumen at the suture line level that cannot be overcome with a $12 \mathrm{~mm}$ endoscope. Obesity was considered in patients with a BMI of 30 or above.

Statistical analysis of the data obtained was performed using MedCalc, , SPSS version 17 and GRAPH Pad Prism. Univariate data analysis was performed using the Chi-square and Fisher tests. The Mann Whitney descriptive statistics test was used. The unanimously accepted significance threshold is $95 \%$, meaning $\mathrm{p}=0.05$. The smaller the value of " $\mathrm{p}$ " with respect to this value, the stronger the significance. Statistical interpretation of the data considered the appropriate differences for a significance threshold:

- $\quad$ p>0.05 statistically insignificant; 
- $\mathrm{p}<0.05$ statistically significant.

\section{Results and discussions}

Following the application of the inclusion and exclusion criteria resulted in a batch of 203 patients with colorectal mechanical anastomoses using a circular stapler. Of these, after the phone questionnaire, it was found that two had already been treated postoperatively for anastomotic stenosis, one via digital dilation and one by radial incisions of the anastomotic line using electrocautery, with progression being favourable in both cases. A percentage of 37.44\% (76 of 203) of patients with colorectal anastomoses reported various postoperative intestinal transit disorders (48 cases of constipation, 19 diarrhoea, alternating constipation-diarrhoea 7, rectorrhagia 10) for which they were invited to undergo endoscopic investigations. Only $52(68.42 \%)$ took part.

Colorectal anastomotic stenosis was found in a total of 7 (3.44\%) patients. Of the 52 patients who had suspicious symptomatology, in $5(9.61 \%)$ cases anastomotic stenosis was endoscopically identified.

The symptomatology of the 7 patients with anastomotic stenoses was represented by constipation in 5 cases $(71.43 \%)$, constipation with diarrhoea in 2 cases $(28.57 \%)$, and rectorrhagia in 6 cases $(85.71 \%)$.

The 48 patients with constipation used laxatives, and the treatment was successful in $44(91.66 \%)$ of them. Of the 10 patients who had reported rectorrhagia, anastomotic stenosis was found in $6(60 \%)$. In all cases, biopsies were obtained, establishing the presence of local recurrence in two patients who were not included in the study.

Demographic analysis showed that of all patients included in the batch, 95 (46.8\%) were female. Of the 7 patients with stenoses, 6 were male (5.55\%), and only one female (1\%). Statistical analysis of the data showed no statistically significant difference between genders in the occurrence of this complication ( $\mathrm{p}=0.1239$, $\mathrm{RR}=1.048$, CI 95\% 0.9963-1.102).

The average age of patients who did not develop stenoses was 66 years, and of those with stenoses, 59 years. A comparative analysis of the postoperative appearance of stenoses in two batches of up to and over 60 years of age yielded statistically significant results in favour of the batch of up to 60 years $(\mathrm{p}=0.008)$.

In our study, $32(15.7 \%)$ patients had diabetes mellitus and 2 of these developed anastomotic stenosis. Of the 171 with no diabetes mellitus, 5 developed anastomotic stenosis. Statistical analysis of the data did not reveal any statistically significant differences as to the appearance of stenoses in patients with diabetes mellitus ( $\mathrm{p}=0.3044, \mathrm{RR}=0.9657$, CI 95\% 0.8798-1.060)

Obesity was present in $23(11.33 \%)$ patients with colorectal anastomoses. Four of them developed anastomotic stenosis. Three patients in the batch with no obesity developed anastomotic stenosis. Statistical analysis shows a correlation between obesity and developing postoperative stenoses ( $\mathrm{p}=0.0036, \mathrm{RR}=1.190$, CI 95\% 0.9858-1.437).

Anaemia, with haemoglobin values lower than $10 \mathrm{mg} / \mathrm{dl}$, was present in 38 (18.7\%) patients, with a single case presenting stenosis ( $\mathrm{p}=1, \mathrm{RR}=1.010$, CI 95\% 0.9515-1.073).

The distribution of colorectal tumour localisation relative to the anal verge in the 203 cases and the incidence of anastomotic stenosis are given in the table below (Table 1).

Table 1. Location of colorectal tumours and anastomotic stenosis

\begin{tabular}{|c|c|c|c|}
\hline Distance from anal verge & No. of cases & No. of stenosis cases & $\%$ \\
\hline $5-6 \mathrm{~cm}$ & 5 & 0 & $0 \%$ \\
\hline $6-8 \mathrm{~cm}$ & 35 & 2 & $5.71 \%$ \\
\hline $8-10 \mathrm{~cm}$ & 71 & 4 & $5.63 \%$ \\
\hline $10-15 \mathrm{~cm}$ & 56 & 1 & $1.78 \%$ \\
\hline $15-20 \mathrm{~cm}$ & 28 & 0 & $0 \%$ \\
\hline$>20 \mathrm{~cm}$ & 8 & 0 & $0 \%$ \\
\hline Total & 203 & 7 & $3.44 \%$ \\
\hline
\end{tabular}


Tumoral complications were present in 49 (24.14\%) patients and were mainly represented by tumoral stenosis. In 7 cases, the tumour penetrated other organs (uterus, urinary bladder, ileum), requiring hysterectomy, partial resection of the urinary bladder and enterectomy, and in 4 cases the tumour was perforated with peritumoral abscess.

Of the 7 anastomotic stenoses, 2 cases were associated with tumoral perforation and one case with urinary bladder resection. One of the two cases of stenosis occurring in tumours with perforation and abscess required repeated pneumatic dilations; however, in the end, reintervention was needed, with the resection of the stenotic area and colorectal reanastomosis. Peritumoral perforation and abscess represents an important risk factor in the appearance of anastomotic stenosis $(\mathrm{p}=0.0059, \mathrm{RR}=1.950)$.

Preoperative mechanical colon preparation was performed in all cases of elective surgery.

Colorectal mechanic resection and anastomosis was done using Griffen's double staple technique [4] in all cases of termino-terminal (T-T) anastomosis using circular staplers with diameters between 28 and $33 \mathrm{~mm}$.

The following staplers were used on patients who developed anastomotic stenosis: 2 of $31 \mathrm{~mm}$ and 5 of $33 \mathrm{~mm}$ in diameter (Table 2). There was no statistical significant difference between the diameter of the stapler and the appearance of anastomotic stenosis $(\mathrm{p}=1)$.

Table 2. Incidence of stenoses relative to stapler diameter

\begin{tabular}{|c|c|c|c|}
\hline Stapler dlameter & No. of cases & No. of stenosis cases & $\%$ \\
\hline 28 & 2 & 0 & 0 \\
\hline 31 & 72 & 2 & $2.77 \%$ \\
\hline 33 & 129 & 5 & $3.87 \%$ \\
\hline Total & 203 & 7 & $3.44 \%$ \\
\hline
\end{tabular}

Anal stenoses were detected at the following distances from the anal verge (Table 3).

Table 3. Location of stenosis relative to anal verge

\begin{tabular}{|c|c|}
\hline Distance from $\mathrm{AV}$ & No. of stenosis cases \\
\hline $4 \mathrm{~cm}$ & 1 \\
\hline $5 \mathrm{~cm}$ & 3 \\
\hline $6 \mathrm{~cm}$ & 2 \\
\hline $7 \mathrm{~cm}$ & 1 \\
\hline
\end{tabular}

Protective stomas were performed in 28 cases (13.8\%), represented by ileostomies (26) and colostomies (2). In 6 cases, ileostomy was performed for anastomotic imperfections found intraoperatively and in 4 cases for anastomotic fistulae. Four of the 7 patients with anastomotic stenosis had protective ileostomy, of which only a single one for anastomotic imperfections. In our statistics, diverting stoma appears as a statistically significant risk factor in the appearance of anastomotic stenosis ( $\mathrm{p}=0.0077, \mathrm{RR}=1.147, \mathrm{CI} 95 \%$ 0.9845-1.336).

Perioperative radiation therapy was performed in $112(55.17 \%)$ patients (35 preoperatively and 77 postoperatively) (Table 4). The remaining 91 patients did not require or consent to radiation therapy. Statistical analysis has shown that perioperative radiation therapy does not represent a risk factor in the appearance of postoperative stenoses ( $\mathrm{p}=1, \mathrm{RR}=0.9972$, CI 95\% 0.9466-1.050).

Table 4. Incidence of anastomotic stenosis relative to radiation therapy

\begin{tabular}{|c|c|c|c|c|}
\hline Radiation therapy & Total & Without stenosis & With stenosis & P \\
\hline Yes & 112 & 108 & 4 & 1 \\
\hline No & 91 & 88 & 3 & \\
\hline
\end{tabular}

Of the 7 patients with anastomotic stenoses, 4 underwent several sessions of endoscopic transanal guided balloon dilation. Dilation sessions were performed at an interval of two months. 
The particulars of patients with anastomotic stenosis are summarized in the table below (Table 5).

Table 5.Synopsis of patients with colorectal anastomotic stenosis

\begin{tabular}{|c|c|c|c|c|c|c|c|c|c|c|c|c|}
\hline घँ & ญ్ّ & 寻 & 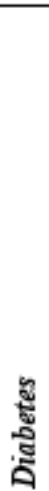 & 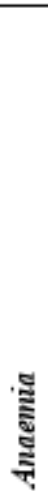 & : & 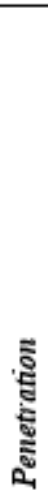 & 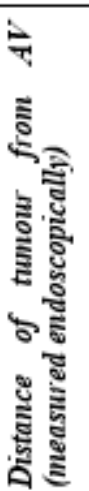 & 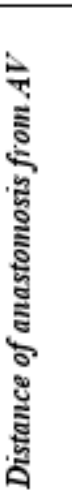 & 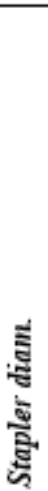 & 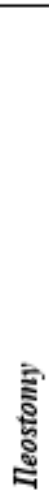 & 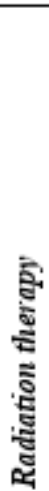 & 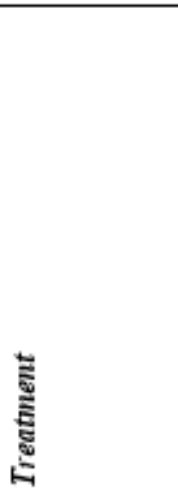 \\
\hline 1 & $M$ & $>30$ & - & - & - & - & $7 \mathrm{~cm}$ & $4 \mathrm{~cm}$ & 33 & $t$ & + & $\begin{array}{l}\text { Digital } \\
\text { dilation }\end{array}$ \\
\hline 2 & $\mathrm{M}$ & $>30$ & + & - & - & - & $8 \mathrm{~cm}$ & $5 \mathrm{~cm}$ & 33 & - & - & $\begin{array}{l}\text { Radial } \\
\text { incisions }\end{array}$ \\
\hline 3 & $\mathrm{M}$ & - & - & - & + & - & $8 \mathrm{~cm}$ & $5 \mathrm{~cm}$ & 33 & + & + & $\begin{array}{l}\text { Pneumatic } \\
\text { dilation }\end{array}$ \\
\hline 4 & $\mathrm{M}$ & - & - & + & - & - & $10 \mathrm{~cm}$ & $6 \mathrm{~cm}$ & 33 & - & - & $\begin{array}{l}\text { Pneumatic } \\
\text { dilation }\end{array}$ \\
\hline 5 & $\mathrm{M}$ & $>30$ & + & - & + & + & $12 \mathrm{~cm}$ & $7 \mathrm{~cm}$ & 31 & + & + & $\begin{array}{l}\text { Dilation + } \\
\text { re-resection }\end{array}$ \\
\hline 6 & $\mathrm{M}$ & - & - & - & - & - & $7 \mathrm{~cm}$ & $5 \mathrm{~cm}$ & 31 & - & - & $\begin{array}{l}\text { Pneumatic } \\
\text { dilation }\end{array}$ \\
\hline 7 & $F$ & $>30$ & - & - & - & - & $8 \mathrm{~cm}$ & $6 \mathrm{~cm}$ & 33 & + & + & $\begin{array}{l}\text { Pneumatic } \\
\text { dilation }\end{array}$ \\
\hline
\end{tabular}

The frequency of benign colorectal anastomotic stenosis described in the literature varies greatly, with values between 3\% and 32\% [4,5]. In our experience, this complication arose at a percentage of $3.44 \%$, with a lower incidence than the average reported in the literature.

The time of diagnosing stenosis in our study was between 30 and 90 postoperative days (median 75, average 62.57, standard deviation 26.42, standard error 9.98). The average time to diagnose anastomotic stenosis reported by Hayden et al. [3] was 204 days (range 17-890 days).

\section{Ethiopathogenesis}

Several researchers [6-8] have attempted to find causes or factors which favour or maintain this process as an expression of inflammatory response; however, not all processes involved in pathological healing are fully understood, and especially the reason why some patients develop this complications, while others do not [9].

There are two factors: general factors that involve individual biology and that are difficult to quantify, and local factors that greatly depend on the quality of the surgical procedure and the materials. Unfavourable local conditions may worsen inflammation, leading to chronic process of healing with continuous tissue lesions followed by repair and regeneration and fibrosis [10].

The suturing material may be a factor involved in the appearance of anastomotic stenosis through its liability of inducing exaggerated local inflammatory processes. The conclusions of studies comparing manual and mechanical anastomosis are controversial concerning the incidence of anastomotic stenosis. Some studies [11] have failed to find a difference between the two techniques, but others [12] have found an increased incidence of stenosis in the case of mechanical anastomoses. The increased incidence of stenoses in the case of mechanical anastomoses does not seem to be connected to the titanium clips themselves, since the material has a high degree of biocompatibility, and cases of allergic reaction to titanium described in the literature are rare $[13,14]$. 
It is supposed that lesion to the colonic mucosa with its apposition defects in the case of mechanical sutures are the causes that induce an increased local inflammatory reaction with the development of strictures [15]. In the case of biodegradable compression rings in anastomoses there is no suture material left. Although there are relatively few retrospective studies about this type of anastomosis, there have still been reported cases of anastomotic stenosis in a percentage of up to $2 \%$ [16-18]. We have not analysed the variable regarding the suture material, since all anastomoses were performed only mechanically.

In the cases we studied we found that the vast majority of anastomotic stenoses were diagnosed at an interval of 1-3 months postoperatively, and the main symptoms were intestinal transit disorders and rectorrhagia. Other authors [19] have reported diagnosing this complication at an average interval of 8 months postoperatively. An endoscopic examination in this time interval would be useful to detect possible stenosis in early stages, with greater chances of achieving a conservative resolution.

In our study we have taken into account both general factors, such as anthropometric ones and patients' comorbidities, and local ones that refer to the characteristics of the tumour and the stapler used as well (Table 6). With regard to surgical technique, there were very few variables, since colorectal resection with mechanical anastomosis is well standardised, with the same anastomosis technique of double stapling being applied in all patients. The only variable element was the diameter of the stapler.

Table 6. Factors analysed for their significance in anastomotic strictures

\begin{tabular}{|l|l|l|l|}
\hline \multicolumn{1}{|c|}{ Factor } & \multicolumn{1}{|c|}{$\begin{array}{c}\text { Stricture } \\
(\mathbf{n = 7})\end{array}$} & \multicolumn{1}{c|}{$\begin{array}{c}\text { No stricture } \\
(\mathbf{n}=\mathbf{1 9 6})\end{array}$} & \multicolumn{1}{c|}{ p value } \\
\hline Age (less than 60 yr) & 5 & 42 & 0.008 \\
\hline Male & 6 & 108 & 0.1239 \\
\hline Distance from anal verge $(<5 \mathrm{~cm})$ & 4 & 72 & 0.4284 \\
\hline Pre-operative haemoglobin $(-10 \mathrm{gm} / \mathrm{dL})$ & 1 & 37 & 1 \\
\hline Diabetes mellitus & 2 & 30 & 0.3044 \\
\hline Obesity & 4 & 19 & 0.0036 \\
\hline Perioperative radiation therapy & 4 & 108 & 1 \\
\hline Diverting stoma & 4 & 24 & 0.0077 \\
\hline Perforated tumour with peritumoral abscess & 2 & 2 & 0.0059 \\
\hline
\end{tabular}

\section{Age and gender}

Although resection with colorectal anastomosis is facilitated in women by their wider pelvis, several studies $[5,19,20]$ found no evidence that the gender of patients would represent a prognostic factor for stenosis. Bradley [21] presents a larger number of men compared to the number of women in the batch of stenoses studied without showing a statistically significant difference. For a number of 195 resections, Polese [22] presents $13 \%$ of stenoses with a statistically significant frequency $(\mathrm{p}=0.01)$ among women. In our study, the frequency of stenosis was larger in men (6/1), without any statistical significance $(\mathrm{p}=0.1239)$. The age of patients was not considered to be an important factor for stenosis by the majority of studies. However, in our study, age under 60 years has statistical significance $(\mathrm{p}=0.008)$. The differences between the different studies are probably due to the presence or absence of associated conditions.

\section{Obesity}

In the literature, results regarding the role of obesity in colorectal anastomotic stenoses are contradictory. A study published in 2013 [23] analyses the impact of obesity on complications and long-term results in patients operated for colorectal cancer and concludes that there is no significant difference between the occurrence of postoperative complications in obese and normal-weight patients.

The results of a study [24] performed on 412 patients with lower colorectal resections show that obesity and smoking are factors associated with anastomotic stenoses following lower rectal resections. Conversely, other authors [5] did not find that obesity and diabetes are significant 
prognostic factors. An article published in 2013 [25] in which the results of all meta-analyses and observational studies published between 1980 and 2012 are collated reached the conclusion that obesity has no significant impact on local postoperative complications.

In our study, $23(11.33 \%)$ patients were obese. Four of them presented anastomotic stenoses. Three patients in the batch with no obesity also developed anastomotic stenoses. The data obtained shows a statistically significant difference $(\mathrm{p}=0.0067, \mathrm{RR}=0.8666$, CI 95\% 0.7396-1.016).

Quantifying the role of obesity is difficult, and we can only speculate on the way it might influence the healing process in anastomosis. One explanation could be the association of diabetes with obesity, which in our study affected $50 \%$ of obese stenotic patients. Moreover, obesity makes more difficult working conditions, especially in men with narrow waists, which leads to longer operating time and more intense trauma to the perianastomotic tissue.

\section{Anaemia}

Although anaemia can generally delay the wound healing by lower oxygen intake, it has been proved that a moderate degree of anaemia has no negative influence on healing, indeed, a moderate decrease in haematocrit is actually beneficial by rheological changes [26,27]. Conversely, an increased blood viscosity due to trauma would have unfavourable effects on the wound healing. Some experimental studies [28] have shown that anaemia has no effect on mechanical resistance of colonic anastomoses in mice. Other experimental studies [29] have encountered a slight increase in production of connective tissue at decreased haematocrit levels. We have found no correlation between anaemia and colorectal anastomotic stenoses in the literature, and anaemia had no influence on this type of complication in our study.

\section{Tumour location}

Regarding the position of the tumour relative to the anal verge, Ashok [19] has found that the localisation closer to the anal verge might be a risk factor for anastomotic stenosis. In our series the occurrence of stenosis was not a statistically influenced by the tumour location $(\mathrm{p}=0.1301)$. Similarly, the level of anastomosis (up to or over $5 \mathrm{~cm}$ ) did not prove to be a factor in the appearance of stenosis $(\mathrm{p}=0.4284$ ), unlike Polese [22], who found anastomosis between 8 and $12 \mathrm{~cm}$ from the anal verge to be a risk factor.

\section{Tumoral complication}

Tumoral complication as the expression of advanced stage seems to have an important role in the incidence of anastomotic stenosis. In the cases we studied, $3(42.85 \%)$ of the 7 cases with stenosis had tumoral complications represented by perforation with abscess and invasion into the urinary bladder. We found that of the 4 cases with local tumour perforation (1.97\% of 203), 2 were later complicated with anastomotic stenosis, which is statistically significant $(\mathrm{p}=0.0059)$. Invasion in other organs occurred in 7 patients, representing $3.45 \%$ of all cases, and was associated with anastomotic stenosis in one case (14.28\% of 7) $(\mathrm{p}=0.2486)$. On the other hand, in a study published by Marchena et al. [29], tumour stage was not an important prognostic factor.

\section{Surgical technique}

Another factor that may matter is that of the surgeon's experience in using staplers. There are studies [31,32] that show an increased incidence of anastomotic fistulae in the case of less-experienced surgeons; however, stapling seems to have an advantage in less-experienced hands [33]. We have found no studies in the literature that correlate the surgeon's experience and anastomotic stenosis.

Anastomotic fistula seems to be an important factor for some authors [34]; conversely, Polese [22] does not identify fistula as a risk factor in the development of postoperative stenoses. The lack of apposition in the colorectal mucosa at the level of anastomosis as a factor that promotes the occurrence of stenosis may be due to certain deficiencies in technique, such as anastomosis under tension [35], 
necrosis of the mucosa due to decreased vascularisation and incomplete resection margins. This latter aspect is considered an independent predictor by Luchtefeld et al. [36]. According to the diameter of the circular stapler used, neither we, nor other authors [37,38] have found any correlation with anastomotic stenosis.

\section{Diverting stoma}

The first study suggesting that a diverting stoma may constitute a factor in the occurrence of stenoses is that of Luchtefeld et al. in 1989 [36]. Subsequently, Polese [22] and Hayden [3] published results with statistically significant values in favour of the involvement of a diverting stoma in the occurrence of stenoses. Lin [39] recognises the role of faecal matter in dilation and recommends closing diverting stomas as soon as possible after the successful dilation of stenoses. In our study as well, $14.3 \%$ in whom protective ileostomy was performed developed anastomotic stenosis, compared to only $1.7 \%$ of the batch without a stoma $(\mathrm{p}=0.0077)$. In our sample, stenoses were not preceded by fistulae. A possible explanation would be the contraction of the anastomotic scar caused by muscular atrophy as a result of the lack of distension at the passage of the faecal bolus [3].

\section{Perioperative radiation therapy}

In our study, radiation therapy did not constitute a risk factor in the appearance of anastomotic stenoses (3.6\% of 112 patients undergoing radiation therapy developed stenoses, compared to 3.3\% with no radiation therapy) $(\mathrm{p}=1)$. Other studies [39] have found that preoperative radiation and anastomotic fistulae are independent prognostic factors, and Hayden [3] found that chemoradiation therapy is a statistically significant predictive factor $(\mathrm{p}=0.04)$ in the occurrence of colorectal stenoses.

\section{Treatment of stenoses}

Anastomotic stenoses can be treated using several methods depending on their location, the degree of stenosis and the response to a minimally invasive treatment. Those in a lower part of the rectum can be efficiently treated via digital dilation. The stenosis ring can be radially incised with electrocauthery or sectioned using a special device, the Steno-Cutter ${ }^{\mathrm{TM}}$ [37]. High stenosis requires an endoscopic approach. Endoscopy is used to visually confirm stenosis, to gauge its stage and its distance from the anal verge, and to obtain biopsies. Under endoscopic control, balloon dilation can be performed, selfexpanding stents can be deployed [40,41], incisions can be made with an electrocauthery [42-44] or various anti-inflammatory agents can be injected. Endoscopic balloon dilation usually requires several session and result in a success rate of $59-100 \%$ [39,43,44,45]. Schlegel [45] reports a $41 \%$ failure rate of dilations that required surgery. He recommends in high stenoses the resection of the stenotic area followed by reanastomosis, and in case of the middle and lower rectum, Soave's procedure. As an alternative to dilation resistant cases, M.J. Forshaw [40] presents an endoscopic transanal resection procedure. Self-expanding stents are a modern, minimally invasive solution, but because of the risk of migration and the difficulty in extracting them means they must be reserved for cases that are resistant to primary treatment methods. An alternative to metallic stents, biodegradable stents are anchored using cyanoacrylate or hemoclips [41]. Not needing subsequent extraction is one of the advantages of biodegradable stents.

Endoscopic dilation procedures are not without risk of complication (restenosis, perforation, abscesses) [40,46], and surgical procedures to widen or re-establish the anastomosis can endanger the patient's life.

In our study, patients undergoing dilation had favourable progression, except for a single refractory case which required reanastomosis and which had an unfavourable progression.

\section{Conclusions}

Colorectal anastomotic stenosis, although of a lower degree of severity than anastomotic fistula, is a complication which alters quality of life in patients. By being aware of the prognostic factors of this 
complication, we would be able to take preventive measures. Unfortunately, there are too many controversial data on this topic in the literature, probably due to the low number of cases, with the vast majority of studies being retrospective ones.

Our results suggest that age under 60 years, obesity, tumour complication by perforation and protective ileostomy could be statistically significant factors for anastomotic stenoses. Other factors such as gender, tumour and anastomosis localisation, anaemia and perioperative radiation therapy seem to have no significant importance. Primary treatment methods are conservative ones using digital or pneumatic dilation depending on the localisation of the stenosis. Surgical treatment is reserved for refractory forms; however, reanastomosis can be hampered by far greater risks than at the first intervention.

Acknowledgment: This study is a part of a project funded through the internal research grants programme of the University of Medicine and Pharmacy of Târgu Mureș, Romania, and financed by SC Coviva RO SRL - contract no. 1478/2015.

\section{References}

1.NEUTZLING CB, LUSTOSA SA, PROENCA IM, DA SILVA EM, MATOS D. Cochrane Database Syst Rev. 15, no 2., 2012

2.JAWHAR LAL SINGHA, ZAHIDUL HAQ, M A MAJID. Chattagram Maa-O-Shishu Hospital Medical College Journal 12, no. 3, 2013, p. 56-61.

3.HAYDEN DM, MARIA PINZON MC, FRANCESCATTI AB, SACLARIDESA TJ. Ann Med Surg (Lond). 4, no. 1, 2015, p. 11-16

4.GRIFFEN FD, KNIGHT CD SR, WHITAKER JM, KNIGHT CD JR. Ann Surg. 211, no. 6, 1990; p 745-51; discussion p. 751-2.

5.AMBROSETTI P, FRANCIS K, DE PEYER R, FROSSARD JL. Dis Colon Rectum. 51, no. 9, 2008, p. 1345-9

6.DUBAY DA, FRANZ MG., Surg Clin N Am. 83, 2003; p. 463-481.

7.ROBSON MC. Surg Clin North Am., 83, no 3, 2003, p. 557-69.

8.STEED DL. Surg Clin North Am., 83, no 3, 2003, p. 547-55

9.RIEDER F, BRENMOEHL J, LEEB S, SCHÖLMERICH J, ROGLER G., Gut. 56, no. 1, 2007, p. 130-139

10.WYNN TA, RAMALINGAM TR. Nat Med., 18, 7, 2012, p. 1028-40

11.LUSTOSA SA, MATOS D, ATALLAH AN, CASTRO AA. Cochrane Database Syst Rev., 3, 2001

12.LUSTOSA SA, MATOS D, ATALlAH AN, CASTRO AA. Sao Paulo Med J., 120, no 5, 2002, p. $132-6$.

13.GOUTAM M, GIRIYAPURA C, MISHRA SK, GUPTA S. Indian J Dermatol., 59, no 6, 2014, p. 630.

14.TIESENGA F, WANG J, CREWS C., CRSLS, 2014.

15.NATHAN SMALLWOOD, MATTHEW G. MUTCH, AND JAMES W. FLESHMAN., Springer Science \& Business Media, 2014, p. 300.

16.GHITULESCU GA, MORIN N, JETTY P, BELLIVEAU P., Can J Surg. 46, no 2, 2003, p. 92-98. 17.KIM SH, CHOI HJ, PARK KJ, KIM JM, KIM KH, KIM MC, KIM YH, CHO SH, JUNG GJ. Dis Colon Rectum., 48, no 11, 2005, p. 2127-32.

18.CORMAN ML, PRAGER ED, HARDY TG JR, BUBRICK MP. Dis Colon Rectum, 32, no 3, 1989, p. 183-7.

19.ASHOK KUMAR, RAM DAGA, PAARI VIJAYARAGAVAN, ANAND PRAKASH, RAJNEESH KUMAR SINGH, ANU BEHARI, VINAY K KAPOOR, AND RAJAN SAXENA. World J Gastroenterol, 17, no 11, 2011, p. 1475-1479

20.BANNURA GC, CUMSILlE MA, BARRERA AE, CONTRERAS JP, MELO CL, SOTO DC. World J Surg., 28, no 9, 2004, p. 921-5. 
21.DAVIS B, RIVADENEIRA DE., Surg Clin North Am., 93, no 1, 2013, p. 61-87.

22.POLESE L, VECCHIATO M, FRIGO AC, SARZO G, CADROBBI R, RIZZATO R, BRESSAN A, Colorectal Dis., 14, no 3, 2012, p. 124-8.

23.AYTAC E, LAVERY IC,. KALADY MF. KIRAN RP. Dis Colon Rectum, 56, no 6, 2013, p.68997

24.KIM MJ, SHIN R, OH HK, PARK JW, JEONG SY, PARK JG. World J Surg., 35, no 12, 2011, p. 2806-10

25.BARDOU M, BARKUN AN, MARTEL M. Gut., 62, no. 6, 2013, p. 933-47.

26.STEED DL. Surg Clin North Am., 83, no 3, 2003, p. 547-55

27.HEUGHAN C, GRISLIS G, HUNT TK. Ann Surg., 179, no. 2, 1974, p. 163-167.

28.TRUEBLOOD HW, NELSEN TS, OBERHELMAN HA. Arch Surg., 99, no. 1, 1969, p. 113-6.

29.HEUGHAN C, GRISLIS G, HUNT TK. Ann Surg., 179, no. 2, 1974, p. 163-167.

30.MARCHENA GÓMEZ J, RUIZ DE LA CUESTA E, GÓMEZ GUERRA G, VALLEJO GALLEGO I, GARCÍA-ANGUÍANO F, HERNÁNDEZ ROMERO JM. Rev Esp Enferm Dig., 89, no. 11, 1997, p. 835-42.

31.KOPERNA T. Arch Surg., 138, no. 12, 2003, p.1334-8; [Discussion:1339].

32.CONG Z, FU C, WANG H, LIU L, ZHANG W, WANG H., World J Surg, 33, no. 6, 2009, p. 1292 $-7$.

33.SLIEKER JC, DAAMS F, MULDER IM, JEEKEL J, LANGE JF. JAMA Surg., 148, no. 2, 2013, p. 190-201.

34.QIN Q, MA T, DENG Y, ZHENG J, ZHOU Z, WANG H, WANG L, WANG J. Dis Colon Rectum. 59, no 10, 2016, p. 934-42

35.HIRANYAKAS A, DA SILVA G, DENOYA P, SHAWKI S, WEXNER SD. Tech Coloproctol. 17, no. 4, 2013, p. 371-5.

36.LUCHTEFELD MA, MILSOM JW, SENAGORE A, SURRELL JA, MAZIER WP. Dis Colon Rectum., 32, no. 9, 1989, p. 733-736.

37.S. SHIMADA, M. KURAMOTO, A. MATSUO, S. IKESHIMA, H. KUHARA, K. ETO AND H. BABA (2012). Dr. Godfrey Lule (Ed.), Pg:187-202.

38.MAHMOUD, NAJJIA N. Difficult Decisions in Colorectal Surgery, 2017, p. 503-508

39.SHAO-CHIEH LIN, EDGAR SY, BO-WEN LIN, JENQ-CHANG LEE. J Soc Colon Rectal Surgeon (Taiwan), 20, 2009, p. 62-68.

40.FORSHAW MJ, MAPHOSA G, SANKARARAJAH D, PARKER MC, STEWART M. Tech Coloproctol., 10, no. 1, 2006, p. 21-27.

41.PÉREZ ROLDAN F, GONZÁLEZ CARRO P, VILLAFANEZ GARCIA MC, AOUFI RABIH S, LEGAZ HUIDOBRO ML, SÁNCHEZ-MANJAVACAS MUNOZ N, RONCERO GARCÍAESCRIBANO O, YNFANTE FERRÚS M, BERNARDOS MARTIN E, RUIZ CARRILLO F. Endoscopy., 44, no. 3, 2012, p. 297-300

42.BRANDIMARTE G1, TURSI A, GASBARRINI G., Endoscopy., 32, no. 6, 2000, p. 461-3.

43.BRAVI I, RAVIZZA D, FIORI G, TAMAYO D, TROVATO C, DE ROBERTO G, GENCO C, CROSTA C. Surg Endosc., 30, no. 1, 2016, p.229-32.

44.HARADA K, KAWANO S, HIRAOKA S, KAWAHARA Y, KONDO Y, OKADA H. Endoscopy. 47,suppl 1, 2015, p. 552-3

45.SCHLEGEL RD, DEHNI N, PARC R, CAPLIN S, TIRET E. Dis Colon Rectum, 44, no. 10, 2001, p.1464-1468.

46.SUCHAN KL, MULDNER A, MANEGOLD BC. Surg Endosc., 17, no. 7, 2003 p. 1110-3.

$\overline{\text { Manuscript received: } 13.09 .2019}$ 